\title{
TEORIA FIGURACIONAL E A TEORIA DAS REPRESENTAÇÕES SOCIAIS: APROXIMAÇÕES E DIÁLOGOS COM NOBERT ELIAS E SERGE MOSCOVICI
}

\author{
Cleberson de Deus Silva (D)1, Edson Pantaleão (D)2 e Lucas de Souza Leite (iD)3
}

\section{Resumo}

O presente texto apoia-se na tarefa de estabelecer possíveis aproximações entre a Teoria Figuracional de Nobert Elias e a Teoria das Representações Sociais, desenvolvida por Serge Moscovici. Para tanto, o ensaio se organiza por meio das seguintes seções: (i) identificação de fragmentos da biografia de ambos os teóricos que possam evidenciar aproximações historiográficas e epistemológicas, e podem ter influenciado em suas opções políticas, teóricas, bem como seus temas de pesquisa; e (ii) análise sobre os conceitos de ancoragem e de objetivação de Moscovici, e os conceitos de figuração, interdependência e equilíbrio de tensões de Elias, buscando explorar suas prováveis conexões. Entre os temas que se destacam na leitura das principais obras elisianas e moscovicianas, estão a produção de conhecimentos, nomeações, imagens, comportamentos e emoções. Partindo dos pressupostos teóricos moscovicianos de ancoragem e de objetivação, formuladas no livro "A Representação Social da Psicanálise", identificamos possíveis conexões entre os conceitos de fantasia coletiva e função objetivadora, utilizadas por Elias e Scotson na obra "Os estabelecidos e os Outsiders".

Palavras-chave: Processo Civilizador; Fantasia Coletiva; Função Objetivadora; Ancoragem.

\section{FIGURATIONAL THEORY AND THE SOCIAL REPRESENTATION THEORY: APPROACHES AND DIALOGUES WITH NORBERT ELIAS AND SERGE MOSCOVICI}

\section{Abstract}

This paper aims to establish possible approaches between the Figurational Theory of Norbert Elias and the Social Representation Theory, developed by Serge Moscovici. For this purpose, the essay is organized through the following sections: (i) identification of fragments of the biography of both theorists that may evidence historiographic and epistemological approaches and may have influenced their political and theoretical options, as well as their research topics. (ii) Analysis on the concepts of anchoring and objectification by Moscovici and

${ }^{1}$ Doutorando em Educação pelo Programa de Pós-Graduação em Educação da Universidade Federal do Espírito Santo (UFES). E-mail: cleberson1612@yahoo.com.br.

${ }^{2}$ Doutor em Educação pela Universidade Federal do Espírito Santo (UFES). Docente no Centro de Educação da UFES.

${ }^{3}$ Mestrando em Educação pelo Programa de Pós-Graduação em Educação da Universidade Federal do Espírito Santo (UFES). 
the concepts of figuration, interdependency and tension balances by Elias, seeking to explore your likely connections. Among the subjects that stand out in the readings of Norbert Elias and Serge Moscovici there are knowledge production, appointments, images, behaviors and emotions. Based on Moscow's theoretical assumptions of anchoring and objectification, formulated in the book "The Social Representation of Psychoanalysis", we identified possible connections between the concepts of collective fantasy and objectifying function, used by Elias and Scotson in the work "The Established and the Outsiders".

Keywords: Civilizing Process; Collective Fantasy; Objectifying Function; Anchoring.

\section{Introdução}

A ideia de construir um texto abordando a Teoria Figuracional de Nobert Elias (1994 e 2011) e a Teoria das Representações Sociais de Serge Moscovici (1978) surgiu com a proposta de pesquisa de doutoramento acerca da trajetória de vida de sujeitos com deficiência da comunidade quilombola de Araçatiba, localizada no município de Viana, Espírito Santo. Com essa intenção, apresentamos algumas ideias embrionárias que, segundo a nossa análise e interpretação, estabelecem aproximações entre as proposições desenvolvidas por Nobert Elias e Serge Moscovici.

Na primeira parte do texto apresentamos, de forma breve, a biografia de ambos os teóricos, que, na nossa avaliação, evidenciam aproximações históricas e epistemológicas. Essa proposta disserta de maneira não cronológica sobre a vida dos autores, com potencial de oferecer prováveis pistas que poderão ajudar a entender melhor as opções políticas e teóricas, bem como os temas de pesquisa desenvolvidos pelos autores em suas investigações científicas.

No segundo momento discutimos, de forma geral, os principais conceitos utilizados pelos autores, a saber: ancoragem e objetivação, de Moscovici (1978); e os conceitos de figuração, interdependência, fantasia coletiva e função objetivadora, de Elias (1994). Também destacamos as principais temáticas afins analisadas pelos autores: produção de conhecimentos, nomeações, (auto)imagens, comportamentos, emoções e crítica aos pressupostos cartesianos, que orientaram o conhecimento científico ocidental numa perspectiva dualista (indivíduo vs. sociedade, racional vs. afetivo, entre outras) de entendimento da realidade social (ELIAS, 1994; MOSCOVICI, 1978).

Na terceira e última parte do artigo, indicamos possibilidades de diálogo entre os conceitos de fantasia coletiva e função objetivadora (utilizadas, especialmente, por Elias e Scotson, na obra Os estabelecidos e os outsiders) e os pressupostos teóricos moscovicianos de ancoragem e de objetivação. Por quê? Conforme Elias e Scotson (1994), os estabelecidos (ou grupos hegemônicos) possuem a necessidade de criar um conjunto de justificativas (ancoragem - fantasia coletiva) e, ao mesmo tempo, dar concretude imagéticas 
(objetivação - função objetivadora/estigma material) às ideias produzidas para legitimar a continuidade de privilégios para determinados grupos sociais.

\section{Trajetórias de vida compartilhadas}

Partindo da ideia de que cada sujeito pode ser visto ao mesmo tempo como uma síntese ou expressão da "sua história pessoal e social, representativa de seu tempo, seu lugar, seu grupo" (GOLDENBERG, 2013, p. 36), abre-se possibilidades de tensionamentos acerca das reflexões sobre a singularidade de cada ser humano e sua relação dialética com seu contexto social e histórico.

Ou seja, a afirmativa anterior apoia-se na ideia de que o sujeito social vai constituindo e nos tornamos o que somos a partir das nossas experiências sociais, resultado da "tensão entre a liberdade individual e o condicionamento dos contextos estruturais" (GOLDENBERG, 2013, p. 36). Por isso, Sartre (1967) corrobora a ideia de que todo ser humano torna-se "um singular universal" (p.126).

Por entender que até mesmo as nossas opções teóricas e a escolha de determinadas temáticas são influenciadas pelas nossas experiências sociais, optamos por realizar um breve relato da trajetória de vida de Nobert Elias (18971990) e Serge Moscovici (1925-2014), principalmente a partir de suas experiências de vida, com diferentes confluências históricas.

Importante ressaltar que os dois autores nasceram na chamada Europa oriental, parte do continente considerado pelas grandes potências econômicas europeias, como culturalmente atrasadas. Do mesmo modo vivenciaram a maior parte da história do século XX, como as grandes guerras mundiais, polarização do mundo entre capitalistas e socialistas, surgimento do neoliberalismo, entre outras confluências históricas. Elias nasceu em Breslávia, cidade que na época pertencia ao Estado Alemão. Depois da $2^{\circ}$ guerra mundial, tornou-se território polonês. Moscovici nasceu na Romênia, cidade de Braila.

Outra semelhança entre ambos é que nasceram em famílias judias, por isso, vivenciarem a exclusão e a discriminação (antissemitismo), no período nazista. Somado a isso, por conta da perseguição e restrições financeiras da família, foram obrigados a interromperem a dedicação exclusiva aos estudos. Em consequência disso, tiveram que exercer profissões manuais como soldador e fundidor para conseguirem se sustentar nos diferentes locais que tiveram que estudar e refugiar.

Pelas narrativas desenvolvidas em seus livros e biografias, a segunda guerra deixou marcas profundas na vida de ambos, pois sentiram a dor de perder familiares e amigos. Nobert Elias (2001, p. 62) ao se referir a seus pais expressa de forma dolorosa a tristeza de perder também contato com a mãe: "Em 1940, minha mãe me escreveu dizendo que meu pai morrera. Ela me escrevia cartas - ainda as tenho comigo. Em seguida, ela desapareceu em Auschwitz... Perdoem-me um instante". 
Segundo Neiburg (2000), Elias se encontrou com seus pais pela ultima vez em 1938, na cidade de Londres. Seu pai, Hermann Elias, morreu em Breslau, em 1940 e sua mãe, Sophie Elias, foi assassinada em Auschwitz, no ano de 1941. Assim como muitos judeus alemães, os genitores de Nobert Elias "demoraram bem mais a perceber que nas relações entre ambos os termos (judeu e alemão) havia se produzido uma alteração que tornava possível o extermínio" (NEIBURG, 2000, p. 10).

Devido ao período de grande encalço nazista, Elias e Moscovici, tiveram que fugir da perseguição e da possível morte, imposta aos judeus, ciganos, negros, entre outros grupos étnicos. Por isso, a peregrinação é mais um traço comum que margeia a trajetória de vida dos autores, como pode ser observado na seguinte reflexão de Moscovici (2005, p. 397): "Meu coração se apertou: os amigos que tive, os acontecimentos terríveis ou providenciais, a fuga de uma opressão de Cîmpouloung, a travessia da fronteira húngara, a fuga de uma opressão para outra, que me levava de país em país".

Com o objetivo de escapar da perseguição e buscar possibilidades mais concretas de estudo e trabalho, ambos foram morar na França. Apesar do amor declarado de Nobert Elias pelo país: "sempre senti um profundo amor pela França. Amava a cultura francesa e falava na época um francês quase perfeito" (ELIAS, 2001, p. 59). No entanto, pela falta de perspectivas Nobert Elias, deixa o país em 1935, pois, segundo ele, "esse país não podia me ajudar em nada. Nenhuma esperança, nenhum futuro" (ELIAS, 2001, p. 60), porque "não tinha chance alguma de arranjar um lugar numa universidade francesa" (ELIAS, 2001, p. 58).

Já Moscovici, no período nazista, foi obrigado a realizar trabalhos forçados. Com o fim da segunda guerra mundial, viveu mais alguns anos na Romênia, até deixá-la, não pela perseguição nazista, mas pelas decisões políticas da União Soviética. Para Moscovici (2005), a luta proclamada contra o capitalismo via Moscou, infelizmente, se descambava para um regime totalitário, com similaridades com o nazismo e fascismo.

A grande perspectiva de um futuro que eu enchera de imagens de uma nova humanidade, de uma revolução sem igual, dissolvia-se na névoa. Só agora eu percebia até que ponto tudo aquilo com que eu tinha sonhado, com seriedade, com paixão, tinha se degradado em elementos de uma simples técnica de poder (MOSCOVICI, 2005, p. 397).

Outro aspecto que podemos identificar como característico entre os dois autores foi a experiência dolorosa da fome. Apesar do glamour proporcionado pela cidade de Paris, Nobert Elias não esconde que vivenciou um dos períodos mais difíceis da sua vida, pois foi o único lugar que passou fome por falta de dinheiro (ELIAS, 2001). Em uma das ocasiões quando acabou todos seus recursos financeiros e ainda faltava trabalho, relata que em um café pediu "a uma amiga que estava sentada a meu lado que me pagasse um café e um sanduíche" (ELIAS, 2001, p. 60). 
Moscovici narra que em dois momentos diferentes de sua vida sentiu fome e não podia saciá-la. A primeira vez foi na juventude, período da Segunda Guerra mundial, quando havia escassez de alimentos e sua família começou a racionar comida.

1942 é um ano da minha vida que detesto me lembrar. Ele começou pelo inverno mais triste e mais miserável. Havia fome, no começo uma intrusa, que roncava e roia você, e, em seguida, uma droga, um estupor, que adormecia o sofrimento cuja consciência, entretanto, persistia. Eu não morria de fome, mas era raro que não me sentisse esfomeado durante o dia. Felizmente, eu tinha boa saúde para suportá-la e sonhar com pão fresco como se fosse uma gulodice (MOSCOVICI, 2005, p. 163).

A segunda vez foi numa viagem da Itália para Paris. Conforme o autor, o sentimento oscilava entre alegria de chegar a tão sonhada capital francesa e o medo do novo, da mudança. O que o ajudou a esquecer esses pensamentos foi "a fome, o calor, e com certeza, o sorriso provocante das viajantes dispersaram aqueles devaneios" (MOSCOVICI, 2005, p. 398).

Depois de uma longa peregrinação pela Itália, Moscovici consegue com amigos entrar na França pela fronteira entre os dois países por locais isolados, tentando evitar o contato com os soldados que faziam a fiscalização e vigilância. Descreve sua chegada a Paris em 1948, com as seguintes palavras: "não havia nada no mundo que eu tivesse esperado mais ansiosamente, durante aquele dia único e inesquecível, do que o fim daquela viagem. Da viagem! Sim, era mesmo em Paris que eu tinha chegado" (MOSCOVICI, 2005, p. 399).

Foi na França que começou a estudar psicologia e lá deu início a sua carreira acadêmica. Inclusive, sua pesquisa de doutoramento foi realizada cidade de Paris na década de 1950. Traduzido para a língua portuguesa, seu trabalho inaugural é intitulado Representações sociais da psicanálise, investigação científica que se tornará reconhecido no âmbito das ciências humanas, principalmente, na psicologia social.

Ambos também tiveram a oportunidade de conhecer e conviver com o filósofo, Alexandre Koyré ${ }^{1}$, grande estudioso da filosofia da ciência do século XX. Os encontros de Elias com Koyré foram em locais informais, como em cafeterias e na própria residência do filósofo.

Eu amava a França, amava Paris, e foi a razão pela qual fiquei ainda mais triste ao constatar que nenhum francês me convidava para ir à casa dele. O que querem? São coisas que eles não fazem. Ou antes, sim, havia um que o fez: Alexandre Koyré, um judeu russo, especialista na história das ideias. Encontrei-me várias vezes com ele (ELIAS, 2001, p. 59).

${ }^{1}$ Seus estudos na área de filosofia e história da ciência influenciaram nomes como Tomas Kuhm e Paul Feyerabend. (c) (i) $($ ) 
Em relação a Serge Moscovici, quando já estava morando em Paris, sentiu necessidade de encontrar um mestre que o auxiliasse em seus estudos. Foi então que conheceu Koyré, e logo percebeu que poderia com ele conciliar convivência saudável com o crescimento intelectual, razão pela qual escolheu seguir os ensinamentos do mestre até a sua morte (MOSCOVICI, 2005).

$\mathrm{O}$ autor de origem romena ainda relata que seu encontro com o mestre foi crucial para que retomasse uma parte do ensaio enviado a uma revista suíça, logo depois do fim Segunda Guerra (1945). Porém, o ensaio foi recusado. Segundo ele, foram as orientações com Alexandre Koyré, "cujo espírito brilhante me fez penetrar na filosofia e na história da ciência. Quando as circunstâncias o permitiram, graças a ele, pude retornar o ensaio que deu nascimento a todo um livro" (MOSCOVICI, 2005, p. 205).

Provavelmente, o que movia a vida desses dois pensadores era o desejo pelo conhecimento. Na leitura das suas biografias, desde a juventude, percebese objetivos comuns: tornarem-se pesquisadores, escritores e professores.

A busca por residirem em grandes centros econômicos, culturais e políticos da Europa não teve apenas como intuito fugir das perseguições políticas - impressões que inferimos com base nas leituras de suas biografias - apenas foram condições concretas que apressaram, muitas vezes, de forma dolorosa para ambos os autores, o sonho de estudarem e trabalharem em grandes instituições de ensino.

Dessa maneira, como possibilidade de uma escrita não cronológica e linear da história de vida dos autores, optamos por elencar alguns fragmentos da vivência de ambos que, em nossa opinião, se aproximam e podem ter influenciado em suas opções políticas, teóricas, bem como seus temas de pesquisa.

\section{Quadro 1: Algumas breves experiências de vida similares de Elias e Moscovici.}

\begin{tabular}{ll}
\hline \multicolumn{1}{c}{ Experiências similares } \\
\hline \multicolumn{1}{c}{ Nobert Elias (1897-1990) } & \multicolumn{1}{c}{ Serge Moscovici (1925-2014) } \\
\hline Nasceu na Polônia (Europa Oriental); & Nasceu na Romênia (Europa Oriental); \\
Família de Judeus; & Família de Judeus e Ciganos; \\
Vivenciou a $1^{\circ}$ e $2^{\circ}$ Guerras Mundiais; & Vivenciou as 20 Guerra Mundial; \\
Perdeu familiares na perseguição nazista; & Perdeu familiares na perseguição nazista; \\
Sofreu discriminação e perseguição; & Sofreu discriminação e perseguição; \\
Residiu na França; & Residiu na França; \\
Conheceu Alexandre Koyré; & Conheceu Alexandre Koyré; \\
Sonho: Professor Universitário. & Sonho: Professor Universitário. \\
\hline
\end{tabular}

Fonte: Elaborado pelos autores (2021).

A proposta é que a partir dos próximos tópicos, abordaremos a teoria de Nobert Elias e Serge Moscovici, passando pelos seus principais conceitos, logo a seguir, traçar um caminho argumentativo, demonstrando as possíveis conexões entre a produção teórica dos respectivos autores. 


\section{A teoria Figuracional de Norbert Elias}

A teoria figuracional de Nobert Elias se caracteriza como tentativa de explicar os fenômenos sociais, problematizando concepções sociológicas contemporâneas sobre indivíduo e sociedade. Debate muito caro nas ciências humanas e sociais, terá como pano de fundo a discussão da relação existente entre a singularidade (sujeito) e a pluralidade de pessoas (sociedade). De acordo com Elias (1994), a maioria das teorias sociológicas interpreta relação entre indivíduo e sociedade como duas "entidades ontologicamente diferentes" (ELIAS, 1994, p. 07). Por isso, realiza críticas a diferentes autores clássicos da sociologia ocidental, dentre eles estão:

Durkheim (1858-1917) e Parsons (1902-1979) e à concepção que eles apresentam de uma interpenetração indivíduo e sociedade. Elias refuta-os lembrando que, para haver interpenetração, é preciso que indivíduo e sociedade existam em separado. Também refuta as perspectivas da existência de um "motor" de mudança externo aos indivíduos (Marx), de mudanças deliberadas racionalmente (Weber) a partir de "indivíduos talentosos" ou de um "espírito exterior" (Hegel) (VEIGA, 2011, p. 149).

Para uma análise mais realista dos problemas sociológicos, Elias (1994 e 2001) adverte sobre a impossibilidade de separação entre indivíduo e sociedade. Por quê? Todos os fenômenos grupais "têm certas particularidades que se distinguem daqueles dos fenômenos individuais, mas sempre é preciso considerar os dois níveis simultaneamente" (ELIAS, 2001, p. 73).

Por isso, cabe ao cientista social, segundo Nobert Elias, "reconhecer a sociedade como uma figuração constituída de numerosos indivíduos fundamentalmente interdependentes, ou seja, tributários e dependentes uns dos outros" (2001, p. 149). Essa forma de entender a realidade, segundo Elias (2001), lança luz à complexidade que é o processo relacional (a condição da existência humana) e ainda contribui para pensar de forma analítica a visão tradicional e polarizada, que coloca de um lado o que vai denominar de atomismo (indivíduo) e de outro o coletivismo sociológico (sociedade) (ELIAS, 2001).

Será em seu livro denominado A sociedade dos indivíduos, que Elias realizará uma análise mais detalhada da relação indivíduo e sociedade. A partir dos estudos realizados nesse trabalho cientifico, Elias (1994) vai mostrar que a sociedade é formada sim por indivíduos, porém essa cria regras próprias, que não podem ser entendidas apenas em função dos indivíduos (ELIAS, 2001). Por isso, se posiciona contrário à concepção de homem hermeneuticamente identificado como sujeito isolado do mundo (homo clausus), ou seja, "um indivíduo totalmente independente, do homem absolutamente autônomo e, portanto, absolutamente livre, constitui o núcleo de uma ideologia burguesa que ocupa um lugar preciso no leque das doutrinas sociais e políticas contemporâneas" (ELIAS, 2001, p. 150 e 151).

Como forma alternativa de reflexão sociológica à concepção de homo clausus e de determinantes sociais, Elias (2001) sugere a seus leitores pensarem 
os sujeitos sociais a partir da diversidade dos homens. O que seria isso? É o movimento continuo de coerções sociais (tema fulcral nas investigações elisianas) produzidas e exercidas por muitos homens, a partir de dependências recíprocas (culturais, sociais, políticas, emocionais, etc.), "produtores de comportamentos e códigos sociais" (VEIGA, 2011, p. 147).

Esses conjuntos de redes de dependência e interdependências humanas, será denominado por Nobert Elias de figuração, que seria a maneira como os seres humanos estão ligados uns aos outros de forma específica e variada. 0 que comumente denominamos de sociedade, é na verdade, segundo Nobert Elias um exemplo de figuração, pois se constitui de:

[...] inúmeros indivíduos fundamentalmente interdependentes, ou seja, tributários e dependentes uns dos outros; só então se é capaz de superar intelectualmente a polarização entre indivíduo e sociedade. Eis um objetivo tão fácil como ovo-de-colombo e tão difícil como a revolução copernicana (ELIAS, 2001, p. 149).

Ao elaborar o conceito de figuração, Elias busca, principalmente, entender a posição desses sujeitos nas diferentes cadeias de dependência, que seriam um conjunto de redes relacionais (relações de interdependência) constituidoras de relações de poder e de controle Desse modo, cada figuração "pressupõem uma rede de interdependências, e suas variações estão relacionadas às diferentes formas de dependência, ou seja, as cadeias de dependência variam de acordo com a complexidade de cada sociedade, com seu contexto funcional" (VEIGA, 2011, p. 147).

Ademais, compreender o conceito de figuração e sua centralidade na sociologia elisiana é fulcral para entender o movimento analítico defendido e desenvolvido pelo autor, porque "o ponto de partida de toda investigação sociológica é uma pluralidade de indivíduos, os quais, de um modo ou de outro, são interdependentes" (ELIAS, 2000, p. 184).

Vale ressaltar que, além das críticas desferidas aos sociólogos clássicos devido às limitadoras concepções da relação sociedade e indivíduo, Nobert Elias (2001) também mira os psicólogos que excluem "todo um processo de desenvolvimento humano" (ELIAS, 2001, p. 64) ao realizarem uma onda de estudos acerca das mentalidades e dos comportamentos apenas baseados em formulários e métodos quantitativos, ou seja, uma tentativa de aplicar procedimentos físicos ou biológicos a seres humanos. Conforme Nobert Elias (2001), seu livro O Processo Civilizador foi um ataque implícito a essa psicologização das relações sociais.

Em meu livro O processo civilizador, eu esperava ter conseguido, com a ajuda de provas empíricas detalhadas, dominar problemas teóricos, sobretudo a mutação civilizadora dos homens e a transformação a longo prazo do estágio de integração do Estado. Esperava que fosse possível às gerações futuras dar sequência a esses trabalhos assim como a outros referentes aos processos sociais de longa duração (ELIAS, 2001, p. 147). 
No mesmo livro, Elias (2011) deixa evidente sua posição acerca da sua visão sobre a relação entre o social e o biológico, debate histórico e acalorado nas instituições universitárias, que, de certa maneira, possui muita relevância para os pesquisadores da educação, como no campo da educação especial.

Ao estudar os livros de etiquetas e boas maneiras, o autor demonstra como os costumes foram se modificando no decorrer dos anos, e que essas mudanças igualmente alteram as estruturas psíquicas dos seres humanos, pois os "processos naturais e históricos trabalham indissoluvelmente juntos" (ELIAS, 2011 , p. 157). Assim como acontece na relação individuo e sociedade, é impossível entender mais profundamente a influência do social e do biológico no desenvolvimento biopsicossocial dos seres humanos se não nos atentarmos para o caráter dialético dessa relação.

Outra questão instigante que emerge das leituras elisianas e que, em nosso entendimento, vão atravessar nossa pesquisa, seria: como pode haver um deslocamento de poder para um determinado grupo? Ou de que forma as mudanças na balança de poderes podem ocasionar alterações na relação entre estabelecidos e outsiders?

Ao Elias e Scotson (2000) estudarem a pequena comunidade de Winston Parva (nome fictício), percebem um traço característico das figurações envolvendo estabelecidos-outsiders: a constante tentativa dos estabelecidos de produzirem e sustentarem imagens positivas e superiores às atribuídas aos outsiders. Como mantinham e puniam os transgressores que tentavam mudar e/ou burlar as regras sociais? Através das fofocas depreciativas. Os elogios eram direcionados aos que observavam as normas (ELIAS; SCOTSON, 2000).

A peça central dessa figuração é um equilíbrio instável de poder, com as tensões que lhe são inerentes. Essa é também a precondição decisiva de qualquer estigmatização eficaz de um grupo outsider por um grupo estabelecido. Um grupo só pode estigmatizar outro com eficácia quando está bem instalado em posições de poder das quais o grupo estigmatizado é excluído (ELIAS; SCOTSON, 2000, p. 23).

Além disso, Elias e Scontson (2000) apontam para a necessidade de produção de uma fantasia coletiva, que seria esse conjunto de ideias depreciativas construídas acerca dos outsiders, como justificadoras de sua exclusão dos bens simbólicos e econômicos. A fantasia coletiva reflete "e, ao tempo, justifica a aversão - o preconceito - que seus membros sentem perante os que compõem o grupo outsiders" (ELIAS; SCOTSON, 2000, p. 35).

Para facilitar o entendimento da ideia de fantasia coletiva, os autores citam como exemplo a opinião difundida entre os japoneses sobre o povo 
burakumim : a crença de que no corpo dos burakumins ${ }^{1}$ existia uma marca hereditária de cor azulada abaixo de suas axilas que os incluíam naturalmente (ou graças aos deuses) nos grupos de párias (ELIAS; SCOTSON, 2000).

Ou seja, antes de se excluir qualquer grupo, se faz necessário primeiramente difundir no imaginário coletivo um conjunto de ideias justificadoras para sua exclusão social e, assim, manter e fortalecer o diferencial de poder dos estabelecidos. De acordo com Elias e Scotson (2000, p. 35), "Isso ilustra muito vividamente a operação e a função das crenças do esblishment a respeito de seus grupos outsiders: o estigma social que seus membros atribuem ao grupo dos outsiders transforma-se em sua imaginação, num estigma material". Da mesma forma, a necessidade de sair do campo abstrato e, dessa maneira, dar mais força, concretude e enraizamento a esse conjunto de concepções, tem sido o caminho comum trilhado também na produção dos estigmas. Esse fenômeno será denominado por Elias e Scotson (2000) como função objetivadora, responsável diretamente pelos diferenciais de poder entre os grupos sociais.

\section{Serge Moscovici e a Teoria das Representações Sociais}

Foi com a publicação em 1961 da obra germinal de Serge Moscovici, intitulada: "La psychanalyse, son image et son public", traduzida para o português como "A representação social da psicanálise", que ocorre a projeção da Teoria das Representações Sociais (TRS) como ferramenta de análise social (FARR, 1995, p. 31). A curiosidade de Moscovici estava em compreender como a sociedade nomeia uma palavra, um objeto sem mesmo conhecê-la. Como os sujeitos que não tiveram contato com a psicanálise aproximavam este conceito da sua realidade? De que maneira o estranho, o perturbador, torna-se palpável e compreensível? Foi isso que Moscovici percebeu quando perguntava o que era e para que servia a psicanálise para seus entrevistados.

Com essa pesquisa, o psicólogo Serge Moscovici inovou e ativou um amplo campo de estudos até então inédito na sua área de formação, classificada por estudiosos como Robert Farr, de uma "forma sociológica da psicologia social" (FARR, 1995, p. 33). Vale lembrar, a inestimável contribuição de Moscovici aos pesquisadores interessados na sociologia do conhecimento. Ele próprio explica como iniciou seus estudos sobre representações:

Por volta dos anos 60, pareceu-me possível retomar o estudo das representações e despertar o interesse de um pequeno grupo de psicólogos sociais, fazendo reviver tal noção. Eles vislumbraram a possibilidade de abordar os problemas de sua disciplina dentro de um novo espírito, de estudar os comportamentos e as relações sociais sem deformá-las nem simplificá-las e de atingir resultados originais (MOSCOVICI, 1978, p. 45).

\footnotetext{
${ }^{1}$ Minoria que vive no Japão. São os responsáveis por realizar os serviços considerados impuros (coveiros, fabricantes de couro, açougueiro, entre outros) e de menor prestígio social. Ainda hoje, esse grupo sofre com permanência do preconceito.
} 
Segundo Moscovici (1978), por séculos o senso comum manteve a primazia sobre as verdades explicativas da vida. O que era certo ou errado, quais eram os remédios para a cura, as explicações dos fenômenos sociais, físicos, bioquímicos. Tudo passava pelo seu crivo. Foi a partir desse conhecimento construído no cotidiano pelos sujeitos sociais que a "ciência e a filosofia dele extraíram seus materiais mais preciosos e os destilavam no alambique de sucessivos sistemas" (MOSCOVICI, 1978, p. 20).

Entretanto, o que se percebe com a primazia da ciência é a inversão desse processo. É ela que propõe a maior parte dos objetos, conceitos que usamos diariamente nas relações econômicas, políticas, sociais, entre outras. As ciências com seus representantes tornam-se sacerdotes ou xamãs modernos que têm ou nos fizeram crer, que os saberes científicos têm todo o domínio das verdades explicativas e resolutivas da vida (MOSCOVICI, 1978).

Como é processado esse conjunto de conceitos científicos que são repassados cotidianamente para grupos sociais que não tiveram a oportunidade de estudá-los metodicamente como se faz na academia? O estudo de Moscovici sobre as representações sociais da psicanálise é um bom exemplo desse fenômeno de reelaboração e tradução do conhecimento. Outro modelo clássico usado por estudiosos para exemplificar a questão da tradução ou preparação de termos científicos ao universo consensual é a pesquisa sobre as representações sociais da Síndrome da Imunodeficiência Adquirida (AIDS).

Logo quando os meios de comunicação começaram a veicular notícias referentes a esta nova doença desconhecida pela grande maioria da população mundial, surgiram várias explicações para a AIDS, entre elas estão: castigo divino, praga homossexual, doença da promiscuidade, peste africana, falta de higiene, entre outras. É o medo do desconhecido que faz com que os seres humanos busquem explicações para esse "novo ameaçador" e cria possibilidades de criação de representações sociais sobre determinado objeto, tornando o não familiar em familiar, agora não mais temível como antes de ocorrer o processo de ancoragem (JOFFE, 1995).

As explicações para esse fenômeno desconhecido, no caso aqui citado, a AIDS, é a objetivação, ou seja, a materialização, a concretude imagética do objeto outrora incógnito (JOFFE, 1995). A TRS sistematiza um processo que ocorre cotidianamente nas relações sociais advindas da necessidade humana de informações e explicações sobre o mundo ao seu redor. São esses saberes que ajudam na vida cotidiana a nomear e definir conjuntamente os diferentes aspectos da realidade diária, no modo de interpretar esses aspectos, tomar decisões e eventualmente, posicionar-se frente a eles de forma defensiva.

Nessa perspectiva, as representações são essencialmente dinâmicas; são produtos de determinações tanto históricas como do aqui-e-agora e construções que têm uma função de orientação: conhecimentos sociais que situam o indivíduo no mundo e, situando-o, definem sua identidade social - o seu modo de ser particular, produto de seu ser social (SPINK, 1995, p. 8). 
Não podemos esquecer-nos de salientar o papel das instituições (escola, igreja, partido político, instituições de ensino superior, entre outros), as redes de comunicação na elaboração das representações sociais, que vale ressaltar, não estão imunes aos mecanismos de manipulação social (JODELET, 2001). Merece destaque o peso das mídias eletrônicas e televisivas que circulam com estrema facilidade por diversos territórios geográficos e sociais.

Esse emaranhado de conteúdos das representações sociais não chega ao individuo e permanece de forma pura, como se fossem meros recipientes vazios. Pelo contrário, todos esses elementos misturam-se aos "sistemas de pensamento mais amplos, ideológicos ou culturais, a um estado dos conhecimentos científicos, quanto à condição social e à esfera da experiência privada e afetiva dos indivíduos" (JODELET, 2001, p. 21).

Esta teoria denominada por representações sociais é conceituada por autores que se debruçam em pesquisá-las como "modalidade de conhecimento particular que tem por função a elaboração de comportamentos e a comunicação entre indivíduos" (MOSCOVICI, 1978, p. 26); "uma forma de conhecimento, socialmente elaborada e partilhada, com um objetivo prático" (JODELET, 2001, p. 22); "uma modalidade de saber gerada através da comunicação na vida cotidiana, com a finalidade prática de orientar os comportamentos em suas situações concretas" (SÁ, 1998, p. 68); "teorias do senso comum" (SÁ, 1995, p. 26).

É pertinente chamarmos à atenção para os cuidados que os pesquisadores precisam ter ao trabalharem com a Teoria das Representações Sociais. Pois, não podem engessar a gênese ou processualidade das representações sociais, ranqueando ancoragem ou objetivação. Autores como Jodelet (2001), Sá (1995) e Leite (2002), além do próprio Moscovici (2009; 1978), ressaltam que esses processos são dialéticos. Ou seja, podem acontecer concomitantemente e com tamanha rapidez que se torna difícil distinguirmos os momentos que cada um acontece. Na verdade, são separadas apenas por questões didáticas. Por foro íntimo, iniciamos pelo processo de ancoragem.

$O$ processo de ancoragem refere-se àquele momento de enraizamento social (SÁ, 1995; JODELET, 2001) da representação e do objeto. O sujeito se esbarra com uma nova ideia, objetos, pessoas ou acontecimentos que, até o momento, the são estranhas. Nesse contexto, ocorre 0 ato de integração cognitiva, ou seja, de aproximação do novo ameaçador ao conjunto de prénoções, experiências e histórias do sujeito social. As representações já existentes podem servir como "sistemas de acolhimento de novas representações sociais" (SÁ, 1995, p. 38). É no processo de ancoragem que "a sociedade converte o objeto social num instrumento de que ela pode dispor, e esse objeto é colocado em uma escala de preferência nas relações sociais existentes" (MOSCOVICI, 1978, p. 173). Por isso, podemos dizer que a ancoragem 
[...] enraíza a representação e seu objeto numa rede de significações que permite situá-lo em relação aos valores e dar-lhe coerência. Entretanto, nesse nível, a ancoragem desempenha um papel decisivo, essencialmente no que se refere à realização de sua inscrição num sistema de acolhimento nocional, um já pensado (JODELET, 2001, p. 38 e 39).

A classificação é inerente ao processo de ancoragem, logo, o sujeito compara e decide a partir do conjunto de histórias estocado na memória. Portanto, o objeto a ser representado pode ser acolhido ou negado ou mesmo alterado. Importante ressaltar, que essa operação não acontece de forma lógica e intencional na mente do sujeito. São momentos que não se tem o domínio das associações que se empreende (SÁ, 1995).

Somado a isso, ocorre a operação de nomeação do objeto estranho, que acaba produzindo uma cadeia de sentidos localizadores e genealógicos que o introduzem na cultura do sujeito (SÁ, 1995). Dois exemplos de ancoragem podem ser vistos na assimilação que as pessoas pesquisadas fizeram da Psicanálise e da AIDS. No primeiro caso, a associação foi feita a uma medicina sem remédio ou a uma confissão religiosa. No segundo caso, o objeto foi ligado a crenças religiosas, interpretando a AIDS como castigo divino aos pervertidos sexuais ou ainda a falta de higiene nas práticas sexuais (LEITE, 2002).

Quando essas representações sociais ganham concretude? É no processo de objetivação que o conhecimento acerca do objeto ganha uma figura quase que tangível (SÁ, 1995). A ideia ganha materialidade, ou seja, acontece a transformação das "ideias e imagens em coisas concretas e materiais que constituem a realidade" (LEME, 1995, p. 49). Um exemplo muito interessante desse processo é "o fato de se comparar Deus a um pai, o que faz com que uma pessoa preencha a mente e desperte os sentimentos correspondentes" (LEME, 1995, p. 49). Na verdade, há um pareamento do conceito com uma imagem. Poderia dizer de forma figurativa que esses conhecimentos se tornaram tão reais e familiares que é possível ao sujeito até mesmo tocá-los.

\section{Diálogos entre os pensadores Norbert Elias e Serge Moscovici}

Depois de algumas incursões na teoria figuracional de Nobert Elias e na Teoria das Representações Sociais de Serge Moscovici, abordando os seus principais conceitos nesse trabalho investigativo, nessa seção serão focalizadas possíveis conexões entre os referidos autores.

Dessa maneira, a proposta deste item é produzir possíveis diálogos e encontros teóricos entre Elias e Moscovici, cuja formulação teórica tornem-se "um conjunto de sinais que sirvam de roteiro" (SIMÕES, 2010, p. 45) para análise e elaboração de futuras pesquisas. Destaca-se que as aproximações teóricas realizadas neste texto, sinalizam possibilidades de outras investidas, em futuras produções, considerando a necessidade de aprofundamentos de debates em outros conceitos que sustentam a produção teórica de Elias e Moscovici. Quando, por exemplo, eles desenvolvem suas obras com uma preocupação 
sociológica atrelada à psicologia. Moscovici um pouco mais que Elias, entretanto, aspectos da psicogênese e da sociogênese, elaborados por Elias, podem incorporar o debate a essas articulações teóricas.

Promovendo o diálogo entre os temas que se destacam na leitura das principais obras elisianas e moscovicianas, estão a produção de conhecimentos, nomeações, imagens, comportamentos e emoções. Por exemplo, no livro 0 processo civilizador, Nobert Elias (2011), mostra como os comportamentos vão se alterando através de processos de longa duração, tornando o que era tido como normal, por exemplo, assoar o nariz com as mãos, como algo posteriormente repugnante. Assim, produzem e difundem a figura do aristocrata que agora passa a utilizar o lenço como regra social típica de sujeitos polidos e educados. Na verdade, se tornam marcadores sociais de poder e prestígio, como bem demonstra Nobert Elias quando ressalta:

Essa tendência explica também o aspecto duplo que os padrões de comportamento e os instrumentos de civilização assumem, pelo menos nesse estágio formativo. Expressam, é certo, um grau de compulsão e renúncia, mas também se transformam imediatamente em arma contra os inferiores sociais, em uma maneira de separar. O lenço, o garfo, os pratos individuais e todos seus implementos correlatos, são no início, artigos de luxo dotados de um valor de prestígio social especial (ELIAS, 2011, p. 149).

Esses como outros exemplos, citados por Elias (2011), corroboram no processo que vai denominar de maleabilidade da vida psíquica. Ou seja, como é criado, propagado e aceito pelos sujeitos sociais determinadas ideias e imagens que, em alguns casos, enaltecem (caso dos estabelecidos) ou excluem e diminuem os grupos sociais outsiders? Elias percebe esse fenômeno de forma empírica quando realiza uma pesquisa de campo com Stcotson na pequena vila inglesa e que vai dar origem ao livro Os estabelecidos e Outsiders (ELIAS; SCOTSON, 2000). Isso tem relação com o "papel desempenhado pela imagem que cada pessoa faz da posição de seu grupo entre outros e, por seguinte, de seu próprio status como membro desse grupo" (ELIAS; SCOTSON, 2000, p. 25 e 26).

Daí surge a primeira e fundamental conexão teórica e de temas afins entre ambos os autores: Serge Moscovici está interessado em compreender essa "modalidade de conhecimento particular que tem por função a elaboração de comportamentos e a comunicação entre indivíduos" (MOSCOVICI, 1978, p. 26). Graças às representações sociais e às atividades psicossociais advindas desse processo, é que conseguimos tornar a realidade ao nosso redor (física e social) compreensível, possibilitando trocas sociais e a libertação da imaginação (MOSCOVICI, 1978).

Essa forma de conhecimento, segundo Moscovici (1978), produz e determina os comportamentos, definindo "simultaneamente a natureza dos estímulos que nos cercam e nos provocam, e o significado das respostas a darIhes" (MOSCOVICI, 1978, p. 26). Por isso, pode tornar-se uma ferramenta 
ideológica para os grupos estabelecidos (hegemônicos) com interesse de produzir comportamentos, imagens e conhecimentos favoráveis à manutenção do status quo. Não é isso que Elias (2000 e 2011) tenta entender ao analisar a história dos costumes através dos livros de etiqueta e da relação entre estabelecidos e outsiders?

Para Elias (2000), naquele contexto social de um pequeno vilarejo (década de 50 do século $X X$ ), a fofoca era o meio difusor de conhecimentos e imagens. Entretanto, não podemos deixar de salientar que as representações sociais (assim como as configurações) não estão protegidas dos mecanismos de manipulação social (JODELET, 2001).

As instituições sociais como escola, universidades, igreja, partido político, especialmente, as mídias eletrônicas e televisivas que circulam com extrema facilidade por diversos territórios geográficos e sociais, exercem papel importante na elaboração das representações sociais (MOSCOVICI, 1978), que são para Nobert Elias, redes de dependência e interdependências humanas, denominadas de figurações (ELIAS, 2011; ELIAS e SCOTSON, 2000).

Por isso, distinguir a estigmatização grupal do preconceito individual, sem relacioná-los é um erro combatido veemente pela teoria elisiana e moscoviciana, pois sua dinâmica relacional (ELIAS 1994) é caracterizada por trocas constantes (MOSCOVICI, 1978) entre grupo e indivíduo.

Partindo dos pressupostos teóricos moscovicianos de ancoragem e objetivação, identificamos também possíveis conexões entre os conceitos de fantasia coletiva e função objetivadora, utilizadas por Elias e Scotson na obra Os estabelecidos e os outsiders.

Na busca por explicações e justificativas para o novo e ameaçador, que pode ser ideias, objetos, acontecimentos, os sujeitos sociais criam, a partir de um conjunto de pré-noções, experiências e histórias de vida, o que autores como Sá (1995) e Jodelet (2001) vão denominar de momento de enraizamento no pensamento social. Em nosso entender, seria o que Elias e Scotson (2000) estão denominando de fantasia coletiva, pois existe por parte dos estabelecidos a necessidade de se criar, contra os que ameaçam a manutenção do equilíbrio de poderes, um conjunto de justificativas para legitimar a continuidade de privilégios para determinados grupos.

Entretanto, para dar materialidade e concretude imagética ao fenômeno, antes encarado como desconhecido e não familiar (JOFFE, 1995), os seres humanos criam imagens associando-as a novas formas de conhecimento. Esse processo chamado por Moscovici (1978) de objetivação, Elias e Scotson (2000) vão denominar de função objetivadora ou estigma material. 


\section{Figura 1: Conceitos e significados similares utilizados por Nobert Elias e Serge Moscovici.}

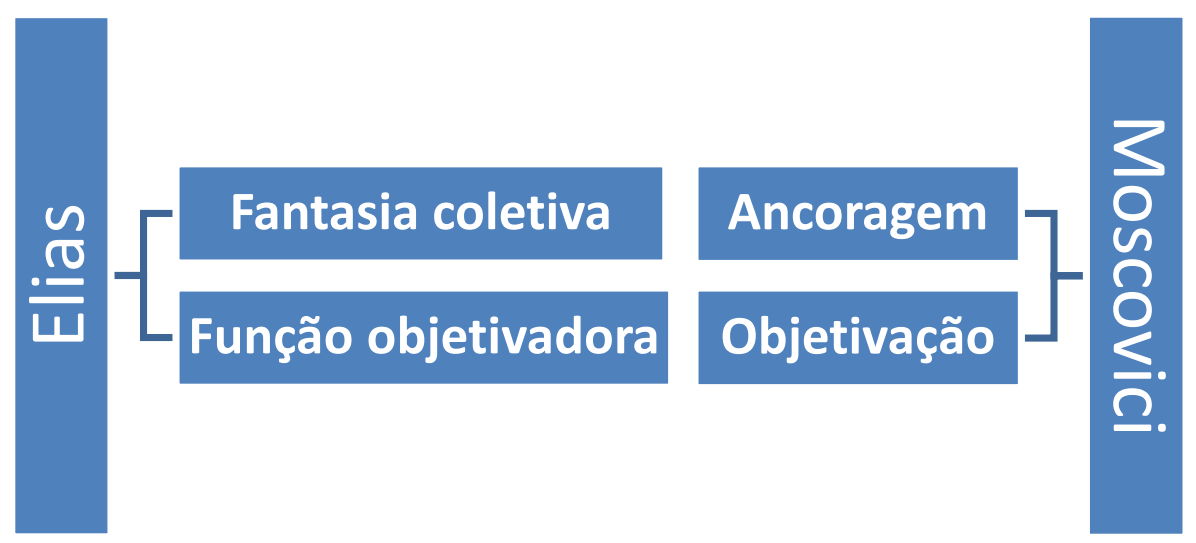

Fonte: Elaborada pelos autores (2021).

Como forma de elucidar o papel negativo que as representações sociais (processos de ancoragem e de objetivação) e determinadas figurações (fantasia coletiva e função objetivadora) podem produzir na relação entre grupos, Elias e Scotson (2000) utilizam o exemplo da "referência à cor diferente da pele e outras características inatas ou biológicas dos grupos que são ou foram tratados como inferiores por grupos estabelecidos" (p. 35).

Quando ressaltamos a importância da produção de imagens e conhecimentos sobre determinado grupo social, como os quilombolas com deficiência, estamos falando, portanto, da possível valorização ou não das culturas, memórias sociais, identidades e autoestima de pertencer a grupos historicamente vistos e tratados como outsiders.

\section{Considerações finais}

A proposta desse estudo consistiu em refletir sobre possíveis aproximações teóricas entre Norbert Elias e Serge Moscovici, com a intenção de construir alternativas analíticas e metodológicas para investigação das interdependências entre os sujeitos sociais - inseridos em grupos, instituições e comunidades tradicionais. Esse esforço sinaliza que novos estudos nesse campo reflexivo podem ser desenvolvidos e aprofundados entre pesquisadores que trabalhem com essas teorias, já que estamos nos referindo a dois autores com diversos livros e artigos publicados em diferentes países, cujas teorias foram e são utilizadas em distintos temas e áreas do saber.

Por fim, destacamos que outras conexões entre os teóricos são possíveis e, posteriormente, poderão ser exploradas em trabalhos acadêmicos futuros, bem como responder (ou não) a supostas incongruências entre a Teoria Figuracional e a Teoria das Representações Sociais. Podemos também destacar a questão da pesquisa que considera o cotidiano, no caso de Elias, que focaliza os costumes de toda uma época, e, no caso de Moscovici, aspectos mais contemporâneos. Além disso, é importante ressaltar que os dois teóricos consideram que as mudanças estruturais somente ocorrem em processos de (1)(8)

Perspectivas em Diálogo, Naviraí, v. 8, n. 17, p. 38-55, maio/ago. 2021. 
longa duração histórica. Essas outras questões nos impulsionam a continuar investindo nessa jornada analítica, que poderá contribuir em estudos futuros no campo das ciências sociais humanas e sociais.

\section{REFERÊNCIAS}

ELIAS, Nobert. A sociedade dos indivíduos. Rio de Janeiro: Zahar, 1994.

ELIAS, Nobert. Nobert Elias por ele mesmo. Rio de Janeiro: Zahar, 2001.

ELIAS, Nobert. O processo civilizador: formação do Estado e civilização. Rio de Janeiro: Zahar, 2011. V. 1.

ELIAS, Nobert; SCOTSON, John. Os estabelecidos e os outsiders: sociologia das relações de poder a partir de uma pequena comunidade. Rio de Janeiro: Zahar, 2000.

GOLDENBERG, Mirian. A arte de pesquisar: como fazer pesquisa qualitativa em Ciências Sociais. Rio de Janeiro: Record, 2013.

JOFFE, Hélène. "Eu não", "o meu grupo não": Representações sociais transculturais da AIDS. In: GUARESCHI, Pedrinho Arcides; JOVCHELOVITCH, Sandra. (Org.). Textos em Representações Sociais. Petrópolis, RJ: Vozes, 1995, p. 297-322.

FARR, Robert Maclaughlin. Representações Sociais: a teoria e sua história. In: GUARESCHI, Pedrinho Arcides; JOVCHELOVITCH, Sandra. (Org.). Textos em Representações Sociais. Petrópolis, RJ: Vozes, 1995, p. 31-59.

JODELET, Denise. Representações sociais: um domínio em expansão. In: JODELET, Denise. (Org.). As representações sociais. Rio de Janeiro: EdUERJ, 2001, p. 31-61.

LEITE, Izildo Corrêa. Desconhecimento, piedade e distância: representações da miséria e dos miseráveis em segmentos sociais não atingidos pela pobreza. Tese (Doutorado em Sociologia) - UNESP: 2002.

LEME, Maria Alice Vanzolini da Silva. O impacto da teoria das representações sociais. In: SPINK, Mary Jane. (Org.). O conhecimento no cotidiano: as representações sociais na perspectiva da psicologia social. São Paulo: Brasiliense, 1995, p. 46-57.

MOSCOVICI, Serge. A representação social da psicanálise. Rio de Janeiro: Zahar, 1978. 
MOSCOVICI, Serge. Crônicas dos anos errantes: narrativa autobiográfica. Rio de Janeiro: Mauad, 2005.

MOSCOVICI, Serge. Preconceito e representações sociais. In: ALMEIDA, Angela Maria de Oliveira; JODELET, Denise. (Org.). Representações Sociais: interdisciplinaridade e diversidade de paradigmas. Brasília, DF: Thesaurus, 2009, p. 19-34.

NEIBURG, Federico. Apresentação à edição brasileira. In: ELIAS, Nobert; SCOTSON, John. Os estabelecidos e os outsiders: sociologia das relações de poder a partir de uma pequena comunidade. Rio de Janeiro: Zahar, 2000, p. 7-11.

SÁ, Celso Pereira. Representações Sociais: o conceito e o estado atual da teoria. In: SPINK, Mary Jane. (Org.). O conhecimento no cotidiano: as representações sociais na perspectiva da psicologia social. São Paulo: Brasiliense, 1995, p. 19-45.

SÁ, Celso Pereira. A construção do objeto de pesquisa em representações sociais. Rio de Janeiro: EDUERJ, 1998.

SARTRE, Jean-Paul. O idiota da família. Porto Alegre: L\&PM, 2014.

SIMÕES, Darcilia. A ciência, a pesquisa, o método: implicações semióticas. In: HENRIQUES, Claudio Cezar; SIMÕES, Darcilia. (Org.). A redação de trabalhos acadêmicos: teoria e prática. Rio de Janeiro: EdERJ, 2010, p. 4155.

SPINK, Mary Jane. Apresentação. SPINK, Mary Jane (Org.). O conhecimento no cotidiano: as representações sociais na perspectiva da psicologia social. São Paulo: Brasiliense, 1995, p. 7-15.

VEIGA, Cynthia Greive. Pensando com Elias as relações entre sociologia e história da Educação. In: FARIA FILHO, Luciano Mendes. Pensadores sociais da educação. Belo Horizonte: Autêntica Editora, 2011, p. 145-172.

Recebido em: 27 de fevereiro de 2021. Aceito em: 13 de maio de 2021. Publicado em: 30 de junho de 2021. 